\title{
Geographic Variation in Medicare Services
}

\section{Citation}

Newhouse, Joseph P., and Alan M. Garber. 2013. “Geographic Variation in Medicare Services." N Engl J Med 368 (16) (April 18): 1465-1468. doi:10.1056/nejmp1302981.

\section{Published Version}

doi:10.1056/NEJMp1302981

\section{Permanent link}

http://nrs.harvard.edu/urn-3:HUL.InstRepos:27351251

\section{Terms of Use}

This article was downloaded from Harvard University's DASH repository, and is made available under the terms and conditions applicable to Other Posted Material, as set forth at http:// nrs.harvard.edu/urn-3:HUL.InstRepos:dash.current.terms-of-use\#LAA

\section{Share Your Story}

The Harvard community has made this article openly available.

Please share how this access benefits you. Submit a story.

\section{Accessibility}



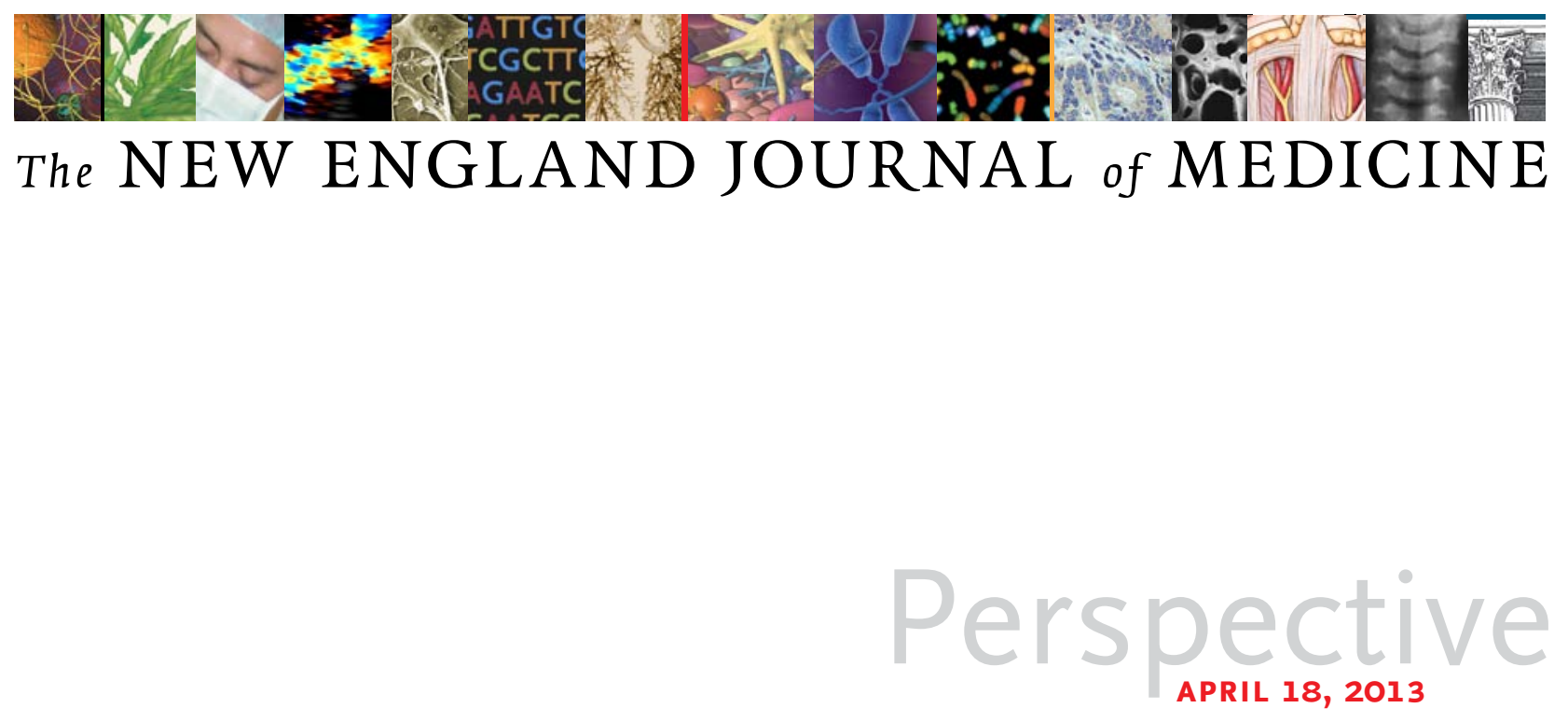

\section{Geographic Variation in Medicare Services}

Joseph P. Newhouse, Ph.D., and Alan M. Garber, M.D., Ph.D.

\section{$\Lambda t$ the request of members of Congress, the In- Astitute of Medicine (IOM) convened a commit- tee to examine geographic variation in Medicare expenditures for the services of hospitals, physicians,}

and other health care providers. In particular, the committee was asked whether Medicare should modify payments to adjust for the value of services delivered in a region by using a value index. Such an index would account for both the health benefit obtained from delivered services and their cost. Payment rates would then be raised in areas where benefits were high relative to Medicare spending and lowered where benefits were low. The committee, which we chaired, commissioned analyses of geographic differences in Medicare payments and has just issued an interim report summarizing and interpreting the findings. ${ }^{1}$ Its full report, due later this year, will also report results of analyses of geo- graphic differences in payments from commercial insurers.

A sizable literature documents that dollars spent per Medicare beneficiary vary greatly among the 306 Dartmouth Hospital Referral Regions (HRRs), which are intended to approximate market areas. $^{2-5}$ However, the consensus ends there. There is controversy about the variation's causes, its effects on quality and outcomes, and what, if anything, should be done about it. Over the past two decades, Congress has tried to reduce the variation through actions such as setting floors for Medicare Advantage benchmarks and using higher wage indexes for low-wage areas. Whatever the merits of such actions, they have done little to eliminate geo- graphic variation in payments. For example in 2007-2009, Medicare spent 1.43 times as much for the average beneficiary in an HRR at the 90th percentile of spending as for the average beneficiary in an HRR at the 10th percentile, even after adjustment for regional levels of wages, rents, and prices for utilities and other services.

Should Medicare seek to reduce these differences? That depends greatly on the causes of variation. Medicare is a national program with nationally determined financing. According to one view, local variation in overall payments largely reflects how aggressively local physicians treat their patients. Absent evidence that more aggressive treatment yields additional benefit, this view supports the use of a value index. An opposing view attributes much of the spending variation to (largely unmeasured) aspects of patients' health status. 
For example, mortality from heart disease varies by a factor of two among states and is strongly correlated with hospitalization rates.

In the literature addressing geographic variation, health status has historically been measured with the use of diagnoses recorded on Medicare claims, which have been the only data available in sufficient quantity to measure health status at a fine geographic level. Analysts who attribute a substantial part of the variation to health status point to the substantial reduction in variation after adjustment for health status, as measured in this fashion, and argue that if health status could be more accurately measured, there would be even larger reductions in variation. But Medicare beneficiaries who move from lower- to higherspending regions have more diagnoses coded after their move, whereas those moving in the opposite direction do not; this suggests that at least some of the variation that is explained by diagnoses on claims forms results from differing coding practices, which may result from differences in the aggressiveness of diagnostic testing. Thus, aggressiveness of care may be a cause of apparent variation in health status, rather than an effect.

Because of these controversies, the IOM committee commissioned analyses that would inform policies to address geographic variation in Medicare expenditures. The committee, informed by the literature and the commissioned studies, made the following observations.

First, a substantial part of the variation across HRRs stems from spending on post-acute care, meaning the use of home health services, skilled nursing facilities, rehabilitation facilities, long-term care hospitals, and hospices. The lowest-spending HRRs tend to spend about $\$ 100$ to $\$ 150$ per beneficiary per month less than the average HRR, and the highestspending HRRs tend to spend about $\$ 100$ to $\$ 150$ more than average (see figure). Areas that are low-spending for all services tend to spend about $\$ 50$ per month per beneficiary less on post-acute care, and high-spending areas tend to spend about $\$ 100$ to $\$ 150$ more. The figure shows why services that are provided after acute care are so important: variation in total spending is strongly associated with variation in spending on these services. Most remaining variation is explained by variation in acute care inpatient services (including physician payments). Other services account for little variation.

Second, the magnitude of spending on post-acute care services in some areas, especially Miami, is suggestive of fraud for example, billing by criminal gangs engaged in identity theft. Any geographic variation in the degree of fraud weakens the case for a value index.

Third, the case for adjusting area reimbursement according to a value index is also weaker when the variation in physician behavior within an area is greater. If behavior within an area is heterogeneous, conservative physicians in areas with lower-value health care will be unjustly penalized and overly aggressive physicians in areas with higher-value care will be unjustly rewarded. To assess variation within an area, the committee used the Dartmouthdefined Hospital Service Areas (HSAs), which are subunits of HRRs (on average, there are 11 HSAs per HRR). We found that more than half the variation in admissions and visits among
HSAs nationally could be attributed to variation among HSAs within an HRR, which indicates that there is substantial variation in treatment within HRRs and weakens the case for adjusting payments according to a geographically based value index.

Fourth, the committee examined spending on several common conditions. It found that spending for one condition within an HRR was not strongly correlated with spending for another. For example, an HRR with aboveaverage spending for treatment of lower back pain might have below-average spending for treatment of cataracts, a finding suggesting that physicians in various specialties within an HRR were not equally aggressive another indication of intra-HRR variation among providers.

Both of these measures of variation in provider behavior among HSAs within HRRs and among physicians treating different conditions within an HRR imply that reimbursement adjustments would be most likely to have the intended effects if targeted at clinical decision-making units rather than entire geographic areas. (The exception is adjustments for wages, rents, and other input prices, which tend to be similar for all providers in the same local area.) Medicare has made a start in this direction by endorsing value-based purchasing and accountable care organizations.

Fifth, the committee looked at the association between an area's spending on certain medical conditions and indicators of its quality of care for that condition. In general, any correlations were small. Moreover, they were positive for some conditions and negative for others, which indicates that uniform changes in an 


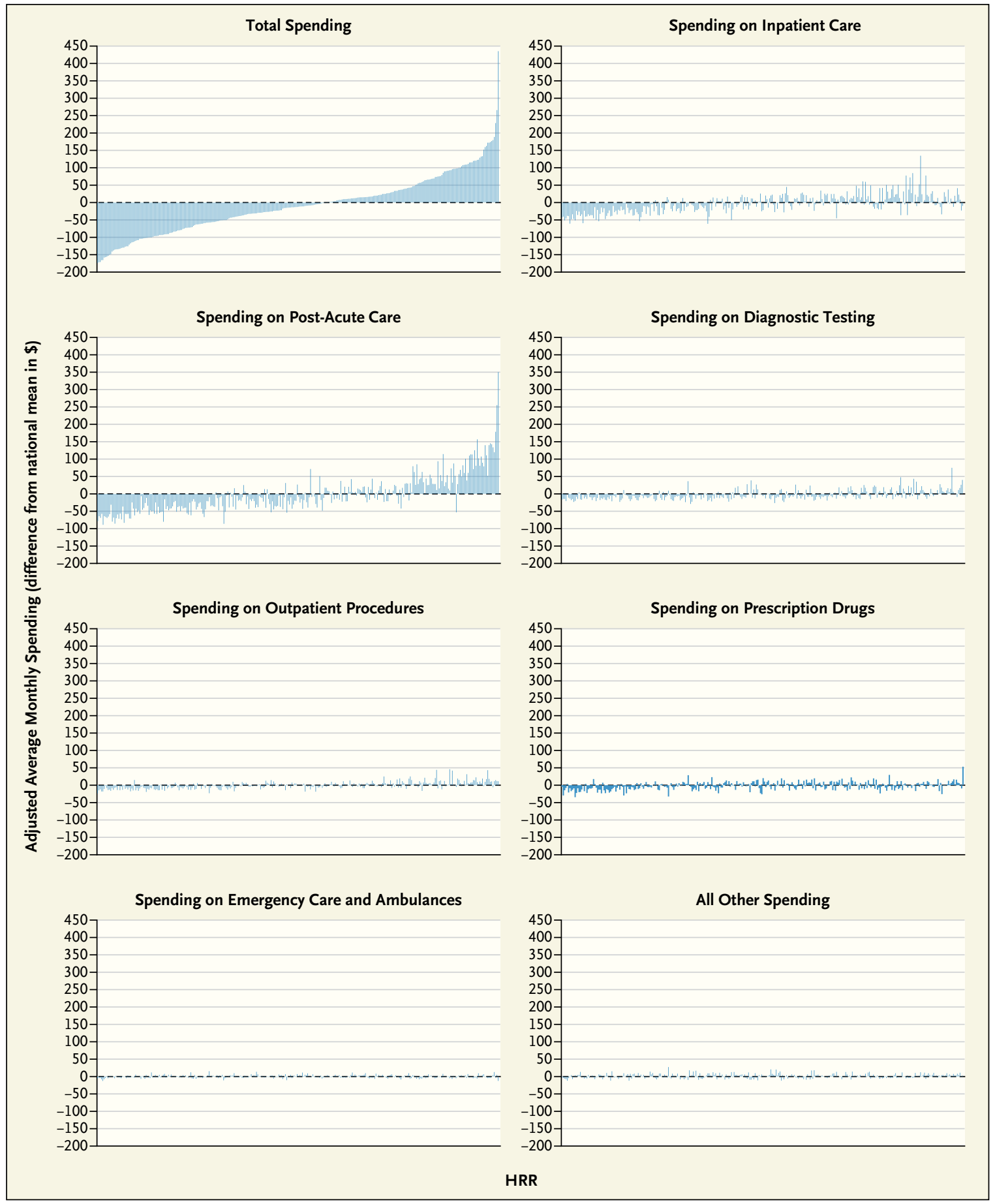

Variation in Adjusted Average Monthly Spending by Medicare per Beneficiary in the 306 Hospital Referral Regions, According to Type of Service, 2007-2009.

Each bar represents a hospital referral region (HRR). In each panel, HRRs are ordered according to the total monthly spending from left to right, ranging from the lowest-spending area after adjustment (Rochester, NY) to the highest-spending area (Miami). Medicare payments for graduate medical education and Disproportionate Share Hospitals are excluded. The vertical axis indicates the difference from the national mean after adjustment for input prices, beneficiary age, sex, age-sex interaction, prior-year diagnoses recorded on claims as coded in terms of CMS-HCCs (Centers for Medicare and Medicaid Services Hierarchical Condition Categories), eligibility for low-income subsidy in Medicare Part D, partial-year enrollment, new-enrollee indicator (prior-year diagnoses not available), and indicators for year (2007, 2008, and 2009). Office visits are included under spending on diagnostic testing. Data are from an analysis performed for the Institute of Medicine by Acumen.

The New England Journal of Medicine

Downloaded from nejm.org on April 6, 2016. For personal use only. No other uses without permission.

Copyright $@ 2013$ Massachusetts Medical Society. All rights reserved. 
area's reimbursement might affect beneficiaries with different conditions differently.

In sum, the committee found that most of the variation among geographic areas is attributable to variation in the use of postacute care and inpatient services. Moreover, within any area, provider behavior varies substantially, so increasing reimbursement for all providers in an area would unfairly reward poorly performing providers, and reducing reimbursement for all providers in an area would unfairly penalize high-performing providers. The committee's interim report contains no recommendations, but we expect to issue a final report with our recommendations this summer.

Disclosure forms provided by the authors are available with the full text of this article at NEJM.org.

From the Department of Health Care Policy, Harvard Medical School, and the Department of Health Policy and Management, Harvard School of Public Health - both in Boston (J.P.N., A.M.G.); and the Harvard Kennedy School (J.P.N., A.M.G.) the Office of the Provost (A.M.G.), and the Department of Economics (A.M.G.), Harvard University - all in Cambridge, MA.

Dr. Newhouse is the chair, and Dr. Garber the vice-chair, of the IOM Committee on Geographic Variation in Health Care Spending and Promotion of High-Value Care; the other committee members are Peter Bach, Joe Baker, Amber Barnato, Robert Bell, Karen Davis, A. Mark Fendrick, Paul Ginsburg, Douglas Hastings, Brent James, Kimberly Johnson, Emmett Keeler, Thomas Lee, Mark McClellan, Sally Morton, Robert Reischauer, Alan Weil, and Gail Wilensky.
This article was published on March 23, 2013, at NEJM.org.

1. Institute of Medicine. Interim report of the committee on geographic variation in health care spending and promotion of highvalue care: preliminary committee observations. Washington, DC: National Academies Press, 2013.

2. Sutherland JM, Fisher ES, Skinner JS. Getting past denial - the high cost of health care in the United States. N Engl J Med 2009;361:1227-30.

3. Zuckerman $\mathrm{S}$, Waidmann $\mathrm{T}$, Berenson R, Hadley J. Clarifying sources of geographic differences in Medicare spending. N Engl J Med 2010;363:54-62.

4. Bach PB. A map to bad policy - hospital efficiency measures in the Dartmouth Atlas. N Engl J Med 2010;362:569-73.

5. Skinner JS, Staiger D, Fisher ES. Looking back, moving forward. N Engl J Med 2010; 362:569-74.

DOI: 10.1056/NEJMp1302981

Copyright (c) 2013 Massachusetts Medical Society.

\section{Leading Clinicians and Clinicians Leading}

Richard M.J. Bohmer, M.B., Ch.B., M.P.H.

tubbornly high costs and the $\checkmark$ expected care needs of aging baby boomers make more effective models of care delivery a pressing need. Unfortunately, new models often perform below their potential. Their designs - usually comprising some combination of alternative sites of care or caregivers, new care processes, and enabling technologies promise global improvements in quality or cost. But successful implementation depends on two local factors: effective care teams and good management of local operations ("clinical microsystems"). Clinicians influence both.

The prospects for care redesign and performance improvement depend on clinician leadership in units, wards, clinics, and practices. Models such as accountable care organizations and patient-centered medical homes presume capable leadership and management. Better organizational performance improves health outcomes, and clinical leadership affects performance. Calls for leadership are common, but the specifics of which clinicians need to do what remain unclear.

Although heads of medical and nursing departments have obvious leadership roles, the need for leadership by clinicians deeper in the organization - usually without any formal title, authority, or leadership job description - is increasingly recognized. Clinical microsystems are composed of and controlled by frontline clinicians whose primary work is patient care. Although many have little interest in leading, the success of health care reform depends on them.

Most definitions of leadership include a focus on a shared goal, dependence on others' actions to reach that goal, and a lack of di- rect control over others. Leaders create conditions that enable and encourage others to achieve a shared goal through collective action - a challenge in health care, since most clinicians were schooled as individualists, don't necessarily view the goal as shared, and generally feel more accountable to professional bodies than local hierarchies.

Front-line clinicians leading local systems have four key tasks. The most important is to establish the group's purpose by emphasizing that the goal is shared and the action needed is collective. Many clinicians presume their organization's purpose is to provide patients with services, and them with clinical resources. Transactional performance measures such as clinic volumes or procedures per operating-room day have reinforced an individualistic perspective. However, recent 